\title{
PERSISTENCE, NON-LINEARITIES AND STRUCTURAL BREAKS \\ IN EUROPEAN STOCK MARKET INDICES
}

\author{
Guglielmo Maria Caporale, Brunel University London, United Kingdom \\ Luis A. Gil-Alana, University of Navarra, Pamplona, Spain, and Universidad Francisco \\ de Vitoria, Madrid, Spain \\ Carlos Poza, Universidad Francisco de Vitoria, Madrid, Spain
}

April 2019

\begin{abstract}
This paper examines persistence, structural breaks and non-linearities in the case of five European stock market indices, namely the FTSE100 (UK), DAX30 (Germany), CAC40 (France), IBEX35 (Spain) and FTSE MIB40 (Italy), using fractional integration methods. The empirical results provide no evidence of non-linearities in either prices or returns; the former are found to exhibit unit roots and the latter to be $\mathrm{I}(0)$ in most cases. Further, between 2 and 4 structural breaks are found for each of the return series, and mean reversion in some subsamples.
\end{abstract}

Keywords: European stock markets; nonstationarity; unit roots; fractional integration; persistence; non-linearities

JEL Classification: C22; C58.

Corresponding author: Professor Guglielmo Maria Caporale, Department of Economics and Finance, Brunel University London, Uxbridge, Middlesex UB8 3PH, UK. Email: Guglielmo-Maria.Caporale@brunel.ac.uk 
* Luis A. Gil-Alana gratefully acknowledges financial support from the Ministerio de Ciencia y Tecnología ((ECO2017-85503-R). 


\section{Introduction}

The Efficient Market Hypothesis (EMH) is still the dominant paradigm to analyse the behaviour of asset prices (see Fama, 1970). Its implication is that prices should follow a random walk, and therefore the order of integration of the log prices series should be one. In its weak form it states that it should not be possible to trade profitably on the basis of historical prices and/or return information. This hypothesis has been tested in numerous empirical studies examining the order of (fractional) integration of the price series as well as persistence and mean reversion (see, e.g., Booth et al., 1982; Peters, 1989; Caporale and GilAlana, 2014, etc.), and also the possible presence of structural breaks (see, e.g., Yuthana and Suthawan, 2012). The methods used include autoregressive and long-range dependence models.

This paper investigates the stochastic properties of five European stock market indices, namely the FTSE100 (UK), DAX30 (Germany), CAC40 (France), IBEX35 (Spain) and FTSE MIB40 (Italy); as in the study carried out by Caporale and Gil-Alana (2014) for the US it uses fractional integration methods but it extends the analysis by allowing for possible structural breaks and non-linearities and using monthly, weekly as well as daily data. The period considered starts in 2009 and has been particularly challenging for the European economies and financial markets, with some EU member states (such as Greece and Portugal) facing a sovereign debt crisis and experiencing cycles of bailouts and austerity. Further, real estate and banking bubbles hit hard the life savings of economic agents in countries such as Spain. The ECB had to adopt new, non-standard monetary policy measures in response to the crisis with the aim of restoring confidence and supporting the availability of credit. For instance, in 2009 it launched the Covered Bond Purchase Programme (CBPP1) purchasing $€ 60$ billion worth of covered bonds between July 2009 and July 2010 with the aim of 
reducing market rates, easing funding conditions to encourage credit institutions to lend to households and firms, and improving market liquidity; this was followed in November 2011 by CBPP2 with the purchase of an additional $€ 40$ billion worth of covered bonds. The ECB also introduced in May 2010 its Securities Markets Programme (SMP) aimed at ensuring the functioning of the monetary policy transmission mechanism through asset purchases; however, these have been sterilised in order not to inject extra liquidity into the system, and therefore this measure cannot be seen as a form of quantitative easing.

In this context, it is of particular interest to examine how prices have behaved in some of the main European stock markets in the recent period. The present study provides new evidence by estimating long-memory models based on the concept of fractional integration that are more general than the standard ones relying on the classical dichotomy between $\mathrm{I}(0)$ and I(1) series and yield a more accurate measure of the degree of persistence of the series. It also investigates whether breaks have occurred and/or prices have evolved in a non-linear fashion.

The layout of the paper is the following: Section 2 provides a brief literature review; Section 3 outlines the methodology; Section 4 describes the data and presents the empirical results; Section 5 offers some concluding remarks.

\section{Literature Review}

Persistence and long memory in stock prices were first analysed by Mandelbrot and van Ness (1968). Subsequently, Greene and Fielitz (1977) showed the presence of a long-term dependence structure in the case of the New York Stock Exchange; Booth et al. (1982) also confirmed that financial series have long memory. Helms et al. (1984) found persistence in futures prices; Peters (1989) used the Rescaled Range statistic for computing Hurst's (1951) 
Exponent in the case of the Standard \& Poor 500 and concluded that returns are affected by investor sentiment.

Poterba and Lawrence (1986) found that volatility is only weakly serially correlated, implying that shocks to volatility do not persist and affect returns only for relatively short intervals, which implies that the poor performance of stock prices during the 1970s cannot be attributed to volatility-induced increases in risk premia. Hinich and Patterson (1985) found non-linearities in the daily rates of return of 15 common stocks using a method based on the bispectrum. Hodula and Bickár (2016) estimated small scale Bayesian models to examine the responses to several macroeconomic variables of the German DAX 30 and the British FTSE 100 indices; they found that the BVAR model outperforms a standard VAR model, with the forecasting accuracy improving from $5 \%$ to $12 \%$, and that the risk premium has a negative effect. Kim et al. (2011) considered the one-minute series for the Korean stock market index (KOSPI); they defined persistence as the time interval over which the index remains above (or below) an initial value and found weak evidence of anti-persistent behaviour.

Yuhn (1996) highlighted the limitations of variance bounds tests and carried out both linear (as in Campbell and Shiller, 1987) and non-linear cointegration tests between stock prices and dividends; his results provide evidence of non-linearities and of random walk behaviour implying weak and semi-strong market efficiency. Humpe and Macmillan (2014) used non-linear smooth transition regression models to examine the predictability of Japanese and US stock market returns on the basis of a set of macroeconomic variables over the period 1981-2012. The underlying theoretical framework is based on the interaction between noise traders and arbitrageurs or behavioural finance theories of non-linear risk aversion, with heterogeneity in investors' beliefs providing the motivation for estimating a smooth transition model; the differences between the Japanese and US stock markets are then explained in terms of share ownership, legal system and heterogeneity. 
As for structural breaks, Yuthana and Suthawan (2012) examined the time variation in return volatility in the Thai Stock Exchange during 1975-2010 using a GARCH framework and carrying out the Bai and Perron's (2003) break tests; they found two breaks in the mean of the conditional volatility of both daily and monthly returns, which most likely are a consequence of policy and regulation changes rather than economic crises. Mehmet et al. (2015) investigated whether the daily stock price indices from 14 emerging markets follow a random walk or a mean-reverting long-memory process; their framework for analysing persistence is more general than the $\mathrm{I}(0) / \mathrm{I}(1)$ paradigm and allows for multiple structural breaks at unknown dates. They found support for the random walk hypothesis for all stock markets except four for which weak evidence of mean-reverting long-memory behaviour was obtained; unit roots were found in all cases except Mexico even when structural breaks were taken into account. In order to check the robustness of their results, they used the two-step feasible exact local Whittle (FELW2ST) estimator of Shimotsu (2006), which allows for polynomial trends, non-normal distributions, and non-stationarity; the results indicate that all stock price series with the exception of Mexico are not mean-reverting.

In a related study, Gil-Alana (2006) used parametric and semi-parametric methods to test for the order of integration of various stock market indices, i.e. the EOE (Amsterdam), DAX (Frankfurt), Hang Seng (Hong Kong), FTSE100 (London), S\&P500 (New York), CAC40 (Paris), Singapore All Shares, and the Japanese Nikkei. In almost all cases the unit root hypothesis could not be rejected; the Hang Seng and the Singapore All Shares were found to exhibit an order of integration higher than 1, whilst for the S\&P500 this is smaller than 1 and there is mean reversion. Caporale and Gil-Alana (2014) examined long-run dynamics and cyclical behaviour using a framework that allows for fractional orders of integration both at the zero (long-run) and the cyclical frequencies. They considered the following US series: inflation, real risk-free rate, real stock returns, equity premium and 
price/dividend ratio, on a yearly basis from 1871 to 1993 . Their results can be summarised as follows. When focusing exclusively on the long run, the estimated order of integration varies considerably, but non-stationarity is found only for the price/dividend ratio. When the cyclical component is also taken into account, the series appear to be stationary but to exhibit long memory with respect to both components in almost all cases. The exception is the price/dividend ratio, whose order of integration is higher than 0.5 but smaller than 1 for the long-run frequency, and is between 0 and 0.5 for the cyclical component. Further, mean reversion occurs in all cases.

In this paper we also analyse stock market indices by using fractional integration methods, but focus on Europe instead and extend the analysis by testing for structural breaks and non-linearities.

\section{Methodology}

Our approach is based on the concept of fractional integration. In order to shed some light on it, note first of all that a process is said to be $\mathrm{I}(0)$ (or integrated of order 0 ) if it is covariance stationary with a spectral density function that is positive and finite at all frequencies in the spectrum. This is usually taken as a minimal requirement for statistical inference, and it includes not only the white noise case but also processes which are weakly autocorrelated such as the stationary autoregressive moving average (ARMA)-class of models.

A time series $\left\{x_{t}, t=1,2, \ldots\right\}$ is then said to be integrated of order d, i.e. $I(d)$, if it can be represented as:

$$
(1-L)^{d} x_{t}=u_{t}, \quad t=1,2, \ldots,
$$


where $\mathrm{L}$ is the lag operator $\left(\mathrm{Lx}_{\mathrm{t}}=\mathrm{x}_{\mathrm{t}-1}\right)$ and $\mathrm{u}_{\mathrm{t}}$ is $\mathrm{I}(0) .{ }^{1} \mathrm{x}_{\mathrm{t}}$ can be the observed time series but also the errors in a regression model including, for example, an intercept, and/or a linear time trend. Many studies have argued that fractional integration is very much related to nonlinearities (e.g. Diebold and Inoue, 2001; Davidson and Terasvirta, 2002; Deo et al., 2006) and therefore, in the present paper, we allow $x_{t}$ to be the errors in a non-linear regression model based on Chebyshev's polynomials in time. Specifically, the first model used is the following one:

$$
y_{t}=\sum_{i=0}^{m} \theta_{i} P_{i T}(t)+x_{t}, \quad(1-L)^{d} x_{t}=u_{t}, \quad t=1,2, \ldots,
$$

where $\mathrm{y}_{\mathrm{t}}$ is the observed series, and $\mathrm{P}_{\mathrm{iT}}$ are the Chebyshev time polynomials defined by:

$$
P_{0, T}(t)=1, P_{i, T}(t)=\sqrt{2} \cos (i \pi(t-0.5) / T), \quad t=1,2, \ldots, T ; \quad i=1,2, \ldots,
$$

where $m$ indicates the degree of non-linearity. ${ }^{2}$ Bierens (1997) and Tomasevic and Stanivuk (2009) argue that it is possible to approximate highly non-linear trends with rather low degree polynomials. In this context, if $m=0$ the model contains an intercept, if $m=1$ it adds a linear trend, and if $m>1$ it becomes non-linear, and the higher $m$ is the less linear the approximated deterministic component becomes. In the empirical analysis below we first estimate the model given by (1) and (2), and, to allow for some degree of generality, we set $\mathrm{m}=3$; the data will contain non-linear structures if $\theta_{2}$ and/or $\theta_{3}$ are statistically significant. We use a procedure developed by Cuestas and Gil-Alana (2016) that allows for both fractional integration and non-linearities of the form given by (2).

It is important to note that the differencing parameter d plays a crucial role in the context of fractional integration. More precisely, if $\mathrm{d}=0, \mathrm{x}_{\mathrm{t}}$ (and thus $\mathrm{y}_{\mathrm{t}}$ ) exhibits short memory and is $\mathrm{I}(0)$, while $\mathrm{d}>0$ implies long-memory behaviour, so-called because of the

\footnotetext{
${ }^{1}$ Note that if $u_{t}$ in $(1)$ is an $\operatorname{ARMA}(p, q)$ process, $x_{t}$ is said to be a fractionally integrated ARMA or ARFIMA(p, $\mathrm{d}, \mathrm{q})$ process.

${ }^{2}$ A detailed description of these polynomials can be found in Hamming (1973) and Smyth (1998).
} 
strong degree of association between observations far apart in time. Also, if $d<0.5, x_{t}$ is covariance stationary, while $\mathrm{d} \geq 0.5$ implies non-stationarity, namely the variance of the partial sums increases in magnitude with $d$; finally, if $d<1$ the series is mean-reverting, with the effects of shocks disappearing in the long run, while $d \geq 1$ implies lack of mean reversion with the effects of shocks persisting forever. Therefore, the parameter $\mathrm{d}$ is very important to determine the degree of persistence of the series: the higher the value of $d$, the higher the degree of persistence is, or alternatively, the lower the value of $\mathrm{d}$ is, the faster the convergence process of a series is to its original level after a shock.

We estimate $d$ by using both parametric and semi-parametric methods. In the former case we use the Whittle function in the frequency domain as proposed in Dahlhaus (1989) and implemented in the tests of Robinson (1994) for the linear case, and Cuestas and GilAlana (2016) for the nonlinear case. The semi-parametric methods used are based on local Whittle estimators (Robinson, 1995, Shimotsu and Phillips, 2006). In addition, the approach proposed by Gil-Alana (2008) to test for structural breaks in a fractional integration framework is also applied. The analysis is carried out using the log-transformed data.

\section{Empirical Analysis}

\subsection{Data Description}

We examine the following five European stock market indices: DAX30 (Germany), FTSE100 (UK), CAC40 (France), FTSE MIB40 (Italy) and IBEX35 (Spain). Open, Close, Low and High prices were initially considered, but given the similarity of the results only those for the closing prices are reported below. Monthly, weekly and daily data are used. The sample period goes from the beginning of January 2009 to the end of January 2019 in the case of monthly and weekly data (121 and 522 observations respectively) and from the beginning of January 2011 to the end January 2019 in the case of daily data (2053 
observations). The data source is Thomson Reuters Eikon. Plots of the series are shown in Figures $1-3$. An upward trend is noticeable in the case of the DAX30, FTSE100 and CAC40, whilst the other two indices are more volatile around a more stable average level.

\section{[Insert Tables $1-3$ about here]}

Tables 1 to 3 report some descriptive statistics for all frequencies. As can be seen, IBEX35 and MIB40 exhibit the most volatile behaviour. In addition, the KolmogorovSmirnov test statistic implies non-normality of the series at the daily and weekly frequency and normality at the monthly one.

\subsection{Empirical Results}

We start by estimating for the logged data the model given by equation (2) that allows for non-linear trends. The results for the monthly, weekly and daily series respectively are reported in Table 4 .

\section{[Insert Table 4 about here]}

There is no evidence of non-linearities, since all the $\theta_{2}$ and $\theta_{3}$ coefficients are not statistically different from zero. As for the fractional differencing parameter $\mathrm{d}$, most of its estimated values are slightly smaller than 1 , and the unit root null hypothesis cannot be rejected in the majority of the cases. The only evidence of mean reversion (i.e., d smaller than 1) is found for weekly data in the case of CAC40 and FTSE100 with weekly data (d being equal to 0.92 in both cases) and MIB40 with daily data (d=0.95).

\section{[Insert Table 5 about here]}

Given the evidence of unit roots in the series reported in Table 4, we take first differences, and carry out the rest of the analysis for the return series. The results for the same non-linear specification are shown in Table 5 and again provide evidence of non-linearities; 
the estimates of $\mathrm{d}$ are now around 0 , and anti-persistence is found in the case of CAC40, FTSE100, MIB40 and IBEX for the weekly series.

The possibility of structural breaks is considered next, since many studies argue that fractional integration might be artificially generated by the presence of breaks in the data that have not been taken into account (Sibbertsen, 2004; Gil-Alana, 2008; Hassler and Meller, 2011; Shao, 2011; Hyang and Shin, 2018; etc.). Specifically, we follow the approach developed by Gil-Alana (2008), which is essentially an extension to the fractional case of the Bai and Perron's (2003) tests for multiple breaks. The results are displayed in Table 6 and indicate that the number of breaks ranges between 2 and 4, the most common break dates being around September 2013, December 2016 and March 2017. The first break can probably be attributed to the anticipation of the US federal government shutdown of October 2013 that affected most routine operations as a result of legislation concerning the allocation of funds for the fiscal year 2014 not being passed in time; this generated concerns about growth in the US and had a negative impact on stock markets throughout the world. The second one coincides with the Fed raising interest rates for the first time in 2016 (from $0.50 \%$ to $0.75 \%$ only the second increase since the financial crisis of 2008), which had negative repercussions for all major stock markets since estimated future cash flows of companies and therefore stock prices dropped. Finally, the third one is around the time when strong US GDP data were released, which led to a surge in the Dow Jones and other indices, accelerating growth in the US usually being seen as positive for stocks in other countries since many companies do business in the US.

\section{[Insert Table 6 about here]}


Next, we estimate the order of integration for each of the subsamples chosen on the basis of the detected breaks. These results are reported in Table 7, 8 and 9 for the monthly, weekly and daily series respectively.

In the case of the monthly series (Table 7) the time trend is not significant in any subsample for the CAC40 index; also, the values of d are substantially smaller for the second and third subsamples, but the unit root null hypothesis cannot be rejected for any of the three subsamples. Concerning DAX30, the time trend is statistically significant during the first subsample, and the same conclusions as for CAC40 hold concerning the order of integration. For MBI40 the time trend is significant in the second subsample and there is evidence of mean reversion since the estimated value of $d(0.57)$ is significantly below 1 ; for IBEX the three estimates of $d$ are rather similar and the unit root null cannot be rejected; finally, for the FTSE100, the time trend is significant in the first subsample and mean reversion occurs in the second subsample. More precisely, mean reversion is found in the case of the monthly series over the subsample $2011 \mathrm{~m} 9-2013 \mathrm{~m} 12$ for the MIB40 and $2013 \mathrm{~m} 1-2016 \mathrm{~m} 12$ for the FTSE100.

\section{[Insert Tables 7 - 9 about here]}

When using weekly data (Table 8) the results for France, Germany and Italy are very similar, the time trend not being significant and evidence of $\mathrm{I}(1)$ behaviour being found in all cases. For the IBEX, a significant (negative) time trend is found in the last subsample and mean reversion takes place in the third and fifth subsamples; in the case of the FTSE100 mean reversion occurs in the second subsample, which is consistent with the results based on monthly data.

Finally, in the case of the daily data (in Table 9) mean reversion takes place in the second subsample for CAC40, in the third one for MBI40, and in the fourth one for IBEX. 


\section{Conclusions}

This paper examines persistence, structural breaks and non-linearities in the case of five European stock market indices, namely the FTSE100 (UK), DAX30 (Germany), CAC40 (France), IBEX35 (Spain) and FTSE MIB40 (Italy), using fractional integration methods. In comparison to a related study by Caporale and Gil-Alana (2014) it focuses on Europe rather than the US and incorporates possible breaks and non-linear structures into the analysis. It sheds new light on the behaviour of stock prices in Europe during a particularly difficult period for the European economies and financial markets as a result of the sovereign debt crisis, real estate and banking bubbles, a credit crunch etc. that made it necessary for the ECB to adopt non-standard monetary policy measures.

The empirical results provide no evidence of non-linearities in either prices or returns; the former are found to exhibit unit roots (which is consistent with market efficiency) and the latter to be $\mathrm{I}(0)$ in most cases. Further, between 2 and 4 structural breaks are found for each of the return series, and mean reversion in some subsamples. The breaks generally correspond to developments in the US that affected stock markets globally. Over the sample as a whole, there seem to be common properties characterising stock prices and returns of all the markets considered (non-stationarity of the former and stationarity of the latter as well as the absence of non-linearities), but the degree of persistence and mean reversion vary across countries and subsamples without any clearly identifiable patterns. 


\section{References}

Bai, J. and P. Perron (2003), Computation and analysis of multiple structural change models, Journal of Applied Econometrics, 18, 1-22

Bierens, H.J. (1997), "Testing the Unit Root with Drift Hypothesis against Nonlinear Trend Stationarity with an Application to the U.S. Price Level and Interest Rate", Journal of Econometrics, 81, 29-64.

Booth, G.; Kaen, F.R. and Koveos, P.E. (1982), Persistent Dependence in Gold Prices. Journal of Financial Research, 5, (1), 85-93.

Campbell, J. Y. and Shiller, R. J. (1987), Cointegration and tests of present value models, Journal of Political Economy, 95, 1062-1088.

Caporale, G.M. and L.A. Gil-Alana (2014), Long Run and Cyclical Dynamics in the US Stock Market, Journal of Forecasting 33, 2, 147-161.

Cuestas J.C. and L.A. Gil-Alana (2016), "A Non-Linear Approach with Long Range Dependence Based on Chebyshev Polynomials", Studies in Nonlinear Dynamics and Econometrics, 23, 445-468.

Dahlhaus, R. (1989), "Efficient Parameter Estimation for Self-Similar Process", Annals of Statistics, 17, 1749-1766.

Davidson, J. And T. Terasvirta (2002), Long memory and nonlinear time series, Journal of Econometrics 110, 2, 105-112.

Deo R., Hsieh M., Hurvich C.M., Soulier P. (2006) Long Memory in Nonlinear Processes. In: Bertail P., Soulier P., Doukhan P. (eds) Dependence in Probability and Statistics. Lecture Notes in Statistics, vol 187. Springer, New York, NY

Diebold, F. and A. Inoue, 2001, Long memory and regime switching, Journal of Econometrics 105, 1, 131-159.

Fama, E.F. 1970, Efficient Capital Markets: A Review of Theory and Empirical Work, The Journal of Finance 25, 2, 383-417.

Gil-Alana, L.A. (2006), Fractional integration in daily stock market index, Review of Financial Economics 15, 28-48.

Gil-Alana, L.A. (2008) Fractional integration and structural breaks at unknown periods of time, Journal of Time Series Analysis 29, 1, 163-185.

Greene, M.T. and Fielitz, B.D. (1977), Long Term Dependence in Common Stock Returns. Journal of Financial Economics, 4, 339-349. Https://doi.org/10.1016/0304-405X(77)90006-X

Hamming, R. W. (1973), Numerical Methods for Scientists and Engineers, Dover: United Kingdom. 
Hassler, U. and B. Meller, 2011, Detecting multiple breaks in long memory. The case of US inflation, Discussion Paper Series 1. Economic Studies 26, Deutsche Bundesbank.

Helms, B.P.; Kaen, F.R. and Rosenman, R.E. (1984), "Memory in commodity futures contracts", Journal of Futures Markets 4, 4, 559-567.

Hinich, M. and Patterson, D. (1985), Evidence of Non-Linearity in Daily Stock Returns. Journal of Business \& Economic Statistics. 3. 69-77. 10.1080/07350015.1985.10509428.

Hodula, M. and Bikár, M. (2016), Stock market price indices modelling by a small scale Bayesian var: The case of British FTSE and German DAX index. Ekonomický casopis. 64. 737-750.

Humpe, A. and Macmillan, P. (2014), Non-linear predictability of stock market returns: Comparative evidence from Japan and the US. Investment Management and Financial Innovations, 11(4).

Hwan Kim, D.; Yong Cha, M. and Lee, J.W. (2011), The persistence probability and the price-price correlation functions in the Korean stock market. Computer Physics Communications. 182. 243-244. 10.1016/j.cpc.2010.06.036.

Hurst, H., 1951, Long term storage capacity of reservoirs, Transactions of the American Society of Civil Engineers, 116, 770-799.

Hyang, E. and D.W. Shin, 2018, Tests for structural breaks in memory parameters of long memory heterogeneous autoregressive models, Communications in Statistics, Theory and Models 47, 21.

Mandelbrot, B. and van Ness, J.W. (1968), Fractional Brownian Motions, Fractional Noises and Applications. SIAM Review, 10, 422-437. Http://dx.doi.org/10.1137/1010093

Mehmet, B.; Esin, C. and Zeynel, O. (2015), Structural Breaks, Long Memory, or Unit Roots in Stock Prices: Evidence from Emerging Markets. International Econometric Review. 7. 1333.

Poterba, J.M. and Lawrence H.S. (1986), "The Persistence of Volatility and Stock Market Fluctuations". American Economic Review, December 1986, pp. 1142-1151.

Robinson, P.M. (1994), "Efficient Tests of Nonstationary Hypotheses", Journal of the American Statistical Association, 89, 1420-1437.

Shao, X. (2011). A simple test of changes in mean in the possible presence of long-range dependence. Journal of Time Series Analysis, 32, 598-606.

Shimotsu, K. and P.C.B. Phillips (2006), Local Whittle estimation of fractional integration and some of its variants. Journal of Econometrics, 130, 209-233.

Sibbertsen, P., 2004, Long memory versus structural breaks. An overview, Statistical Papers $45,4,465-515$. 
Smyth, G.K. (1998), Polynomial Approximation, John Wiley \& Sons, Ltd, Chichester: United Kingdom.

Tomasevic, N.M. and T. Stanivuk (2009), "Regression Analysis and Approximation by Means of Chebyshev Polynomial", Informatologia, 42, 166-172.

Yuhn, K.H. (1996), Stock price volatility: tests for linear and non-linear cointegration in the present value model of stock prices, Applied Financial Economics, 6:6, 487-494, DOI: $10.1080 / 096031096333935$.

Yuthana, S. and Suthawan, P. (2012), Structural Breaks in Stock Returns Volatility: Evidence from the Stock Exchange of Thailand. Empirical Econometrics and Quantitative Economics Letters. 
Table 1. Descriptive Statistics - Daily data

\begin{tabular}{|c|c|c|c|c|c|c|}
\hline & $\mathrm{N}$ & Minimum & Maximum & Mean & Std. Deviation & $\begin{array}{l}\text { Asymp. Sig. } \\
\text { (2-tailed). } \\
\text { Kolmogorov- } \\
\text { Smirnov Test }\end{array}$ \\
\hline IBEX35_OPEN & 2053 & 5950,40 & 11798,50 & 9446,49 & 1158,92 & 0,000 \\
\hline IBEX35_CLOSE & 2053 & 5956,30 & 11866,40 & 9441,69 & 1159,08 & 0,000 \\
\hline IBEX35_LOW & 2053 & 5905,30 & 11760,80 & 9362,92 & 1163,81 & 0,000 \\
\hline IBEX35_HIGH & 2053 & 6093,10 & 11884,60 & 9516,13 & 1153,02 & 0,000 \\
\hline DAX30_OPEN & 2053 & 5063,59 & 13577,14 & 9611,14 & 2192,79 & 0,000 \\
\hline DAX30_CLOSE & 2053 & 5072,33 & 13559,60 & 9609,14 & 2191,40 & 0,000 \\
\hline DAX30_LOW & 2053 & 4965,80 & 13517,81 & 9542,99 & 2189,21 & 0,000 \\
\hline DAX30_HIGH & 2053 & 5126,52 & 13596,89 & 9671,91 & 2195,59 & 0,000 \\
\hline CAC40_OPEN & 2053 & 2754,82 & 5637,94 & 4368,58 & 707,90 & 0,000 \\
\hline CAC40_CLOSE & 2053 & 2781,68 & 5640,10 & 4367,98 & 707,82 & 0,000 \\
\hline CAC40_LOW & 2053 & 2693,21 & 5628,93 & 4338,45 & 710,12 & 0,000 \\
\hline CAC40_HIGH & 2053 & 2823,97 & 5657,44 & 4395,88 & 705,81 & 0,000 \\
\hline MIB40_OPEN & 2053 & 12357,70 & 24488,45 & 19216,29 & 2837,89 & 0,000 \\
\hline MIB40_CLOSE & 2053 & 12362,51 & 24544,26 & 19206,20 & 2837,52 & 0,000 \\
\hline MIB40_LOW & 2053 & 12295,76 & 24274,65 & 19035,31 & 2849,87 & 0,000 \\
\hline MIB40_HIGH & 2053 & 12656,38 & 24544,26 & 19377,20 & 2823,21 & 0,000 \\
\hline FTSE100_OPEN & 2053 & 4944,44 & 7877,45 & 6540,03 & 646,69 & 0,000 \\
\hline FTSE100_CLOSE & 2053 & 4944,44 & 7877,45 & 6540,69 & 646,40 & 0,000 \\
\hline FTSE100_LOW & 2053 & 4791,01 & 7854,58 & 6502,35 & 652,93 & 0,000 \\
\hline FTSE100_HIGH & 2053 & 5075,50 & 7903,50 & 6577,10 & 641,35 & 0,000 \\
\hline Valid N (listwise) & 2053 & & & & & \\
\hline
\end{tabular}


Table 2. Descriptive Statistics - Weekly data

\begin{tabular}{|c|c|c|c|c|c|c|}
\hline & $\mathrm{N}$ & Minimum & Maximum & Mean & Std. Deviation & $\begin{array}{l}\text { Asymp. Sig. } \\
\text { (2-tailed). } \\
\text { Kolmogorov- } \\
\text { Smirnov Test }\end{array}$ \\
\hline IBEX35_OPEN & 522 & 5998,90 & 12192,50 & 9603,13 & 1207,57 & 0,011 \\
\hline IBEX35_CLOSE & 522 & 6065,00 & 12163,00 & 9599,12 & 1202,39 & 0,005 \\
\hline IBEX35_LOW & 522 & 5905,30 & 11986,10 & 9373,20 & 1215,27 & 0,013 \\
\hline IBEX35_HIGH & 522 & 6578,50 & 12240,50 & 9795,26 & 1193,82 & 0,002 \\
\hline DAX30_OPEN & 522 & 3677,07 & 13459,42 & 8848,81 & 2559,60 & 0,000 \\
\hline DAX30_CLOSE & 522 & 3666,41 & 13478,86 & 8856,85 & 2551,60 & 0,000 \\
\hline DAX30_LOW & 522 & 3588,89 & 13222,47 & 8682,54 & 2535,44 & 0,000 \\
\hline DAX30_HIGH & 522 & 3891,71 & 13596,89 & 9003,58 & 2568,31 & 0,000 \\
\hline CAC40_OPEN & 522 & 2552,99 & 5626,70 & 4207,56 & 731,93 & 0,029 \\
\hline CAC40_CLOSE & 522 & 2534,45 & 5614,51 & 4209,50 & 730,31 & 0,030 \\
\hline CAC40_LOW & 522 & 2465,46 & 5524,44 & 4126,21 & 736,72 & 0,058 \\
\hline CAC40_HIGH & 522 & 2675,68 & 5657,44 & 4280,47 & 722,87 & 0,021 \\
\hline MIB40_OPEN & 522 & 12643,94 & 24355,16 & 19476,01 & 2781,94 & 0,001 \\
\hline MIB40_CLOSE & 522 & 12739,98 & 24335,02 & 19477,10 & 2771,58 & 0,001 \\
\hline MIB40_LOW & 522 & 12295,76 & 23871,01 & 18993,94 & 2802,44 & 0,001 \\
\hline MIB40_HIGH & 522 & 13317,69 & 24558,46 & 19894,64 & 2738,35 & 0,001 \\
\hline FTSE100_OPEN & 522 & 3530,73 & 7778,79 & 6246,80 & 883,36 & 0,006 \\
\hline FTSE100_CLOSE & 522 & 3530,73 & 7778,79 & 6251,55 & 880,34 & 0,006 \\
\hline FTSE100_LOW & 522 & 3460,71 & 7703,26 & 6152,54 & 893,93 & 0,013 \\
\hline FTSE100_HIGH & 522 & 3816,02 & 7903,50 & 6334,73 & 868,04 & 0,017 \\
\hline Valid N (listwise) & 522 & & & & & \\
\hline
\end{tabular}


Table 3. Descriptive Statistics - Monthly data

\begin{tabular}{|c|c|c|c|c|c|c|}
\hline & $\mathrm{N}$ & Minimum & Maximum & Mean & Std. Deviation & $\begin{array}{l}\text { Asymp. Sig. } \\
\text { (2-tailed). } \\
\text { Kolmogorov- } \\
\text { Smirnov Test }\end{array}$ \\
\hline IBEX35_OPEN & 121 & 6109,70 & 11986,50 & 9608,57 & 1207,68 & 0,176 \\
\hline IBEX35_CLOSE & 121 & 6089,80 & 11940,00 & 9602,03 & 1197,33 & 0,138 \\
\hline IBEX35_LOW & 121 & 5905,30 & 11468,70 & 9102,99 & 1216,32 & 0,159 \\
\hline IBEX35_HIGH & 121 & 7102,20 & 12240,50 & 9999,84 & 1171,53 & 0,180 \\
\hline DAX30_OPEN & 121 & 3817,51 & 13342,44 & 8840,15 & 2574,11 & 0,206 \\
\hline DAX30_CLOSE & 121 & 3843,74 & 13229,57 & 8882,71 & 2550,41 & 0,187 \\
\hline DAX30_LOW & 121 & 3588,89 & 12849,59 & 8470,20 & 2518,55 & 0,253 \\
\hline DAX30_HIGH & 121 & 4272,12 & 13596,89 & 9174,87 & 2596,44 & 0,070 \\
\hline CAC40_OPEN & 121 & 2632,92 & 5524,38 & 4209,63 & 735,58 & 0,609 \\
\hline CAC40_CLOSE & 121 & 2702,48 & 5520,50 & 4219,09 & 729,88 & 0,503 \\
\hline CAC40_LOW & 121 & 2465,46 & 5381,38 & 4026,26 & 738,70 & 0,636 \\
\hline CAC40_HIGH & 121 & 2918,23 & 5657,44 & 4359,88 & 717,11 & 0,441 \\
\hline MIB40_OPEN & 121 & 12919,19 & 24014,71 & 19484,63 & 2725,56 & 0,168 \\
\hline MIB40_CLOSE & 121 & 12873,84 & 23979,37 & 19467,11 & 2702,38 & 0,148 \\
\hline MIB40_LOW & 121 & 12295,76 & 22725,83 & 18383,35 & 2747,28 & 0,088 \\
\hline MIB40_HIGH & 121 & 14274,37 & 24558,46 & 20366,63 & 2670,76 & 0,185 \\
\hline FTSE100_OPEN & 121 & 3830,09 & 7748,76 & 6232,93 & 893,19 & 0,523 \\
\hline FTSE100_CLOSE & 121 & 3830,09 & 7748,76 & 6253,55 & 880,03 & 0,504 \\
\hline FTSE100_LOW & 121 & 3460,71 & 7540,71 & 6035,59 & 911,60 & 0,409 \\
\hline FTSE100_HIGH & 121 & 3992,42 & 7903,50 & 6420,37 & 862,83 & 0,210 \\
\hline Valid N (listwise) & 121 & & & & & \\
\hline
\end{tabular}


Table 4: Estimated coefficients in a nonlinear $I(d)$ model for the log prices series

\begin{tabular}{|c|c|c|c|c|c|}
\hline \multicolumn{6}{|c|}{ i) Monthly data } \\
\hline Series & $\mathrm{d}$ & $\theta_{0}$ & $\theta_{1}$ & $\theta_{2}(\mathrm{NL})$ & $\theta_{3}(\mathrm{NL})$ \\
\hline FRANCE & $\begin{array}{c}0.90 \\
(0.77,1.07)\end{array}$ & $\begin{array}{l}8.1925 \\
(46.50)\end{array}$ & $\begin{array}{c}-0.1603 \\
(-1.56)\end{array}$ & $\begin{array}{l}0.0096 \\
(0.16)\end{array}$ & $\begin{array}{l}0.0133 \\
(0.33)\end{array}$ \\
\hline GERMANY & $\begin{array}{c}0.91 \\
(0.77,1.10)\end{array}$ & $\begin{array}{l}8.8734 \\
(43.46) \\
\end{array}$ & $\begin{array}{c}-0.2950 \\
(-2.47)\end{array}$ & $\begin{array}{c}-0.0463 \\
(-0.70) \\
\end{array}$ & $\begin{array}{c}-0.0105 \\
(-0.23)\end{array}$ \\
\hline ITALY & $\begin{array}{c}0.90 \\
(0.78,1.10)\end{array}$ & $\begin{array}{l}9.7187 \\
(40.23) \\
\end{array}$ & $\begin{array}{c}-0.0429 \\
(-0.30) \\
\end{array}$ & $\begin{array}{l}0.0413 \\
(0.52) \\
\end{array}$ & $\begin{array}{l}0.0533 \\
(0.97) \\
\end{array}$ \\
\hline SPAIN & $\begin{array}{c}0.93 \\
(0.81,1.09)\end{array}$ & $\begin{array}{l}8.9606 \\
(36.36) \\
\end{array}$ & $\begin{array}{l}-0.0186 \\
(-0.12)\end{array}$ & $\begin{array}{l}0.0207 \\
(0.26)\end{array}$ & $\begin{array}{l}0.0564 \\
(1.04)\end{array}$ \\
\hline U.K. & $\begin{array}{c}0.85 \\
(0.73,1.00)\end{array}$ & $\begin{array}{l}8.6235 \\
(77.14) \\
\end{array}$ & $\begin{array}{c}-0.1350 \\
(-2.09)\end{array}$ & $\begin{array}{c}-0.0364 \\
(-0.95) \\
\end{array}$ & $\begin{array}{c}-0.0348 \\
(-1.28)\end{array}$ \\
\hline \multicolumn{6}{|c|}{ i) Weekly data } \\
\hline Series & $d$ & $\theta_{0}$ & $\theta_{1}$ & $\theta_{2}(\mathrm{NL})$ & $\theta_{3}(\mathrm{NL})$ \\
\hline FRANCE & $\begin{array}{c}0.92^{*} \\
(0.86,0.99)\end{array}$ & $\begin{array}{l}\mathbf{8 . 1 9 1 6} \\
(39.58)\end{array}$ & $\begin{array}{c}-0.1569 \\
(-1.27)\end{array}$ & $\begin{array}{l}0.0145 \\
(0.21)\end{array}$ & $\begin{array}{l}0.0138 \\
(0.29)\end{array}$ \\
\hline GERMANY & $\begin{array}{c}0.96 \\
(0.89,1.03)\end{array}$ & $\begin{array}{l}8.8598 \\
(33.56)\end{array}$ & $\begin{array}{c}-0.2913 \\
(-1.84)\end{array}$ & $\begin{array}{c}-0.0371 \\
(-0.44)\end{array}$ & $\begin{array}{c}-0.0100 \\
(-0.17)\end{array}$ \\
\hline ITALY & $\begin{array}{c}0.98 \\
(0.92,1.05) \\
\end{array}$ & $\begin{array}{l}9.7369 \\
(26.95) \\
\end{array}$ & $\begin{array}{c}-0.0347 \\
(-0.16) \\
\end{array}$ & $\begin{array}{c}0.0499 \\
(0.45) \\
\end{array}$ & $\begin{array}{c}0.0541 \\
(0.72) \\
\end{array}$ \\
\hline SPAIN & $\begin{array}{c}0.93 \\
(0.87,1.00)\end{array}$ & $\begin{array}{l}8.9725 \\
(35.17) \\
\end{array}$ & $\begin{array}{c}-0.0177 \\
(-0.11)\end{array}$ & $\begin{array}{l}0.0239 \\
(0.29)\end{array}$ & $\begin{array}{l}0.0553 \\
(0.97)\end{array}$ \\
\hline U.K. & $\begin{array}{c}0.92^{*} \\
(0.85,0.99)\end{array}$ & $\begin{array}{l}\mathbf{8 . 6 0 8 9} \\
(\mathbf{5 3 . 2 0}) \\
\end{array}$ & $\begin{array}{l}-0.1301 \\
(-1.35) \\
\end{array}$ & $\begin{array}{c}-0.0325 \\
(-0.61) \\
\end{array}$ & $\begin{array}{c}-0.0349 \\
(-0.96) \\
\end{array}$ \\
\hline \multicolumn{6}{|c|}{ iii) Daily data } \\
\hline Series & $d$ & $\theta_{0}$ & $\theta_{1}$ & $\theta_{2}(\mathrm{NL})$ & $\theta_{3}(\mathrm{NL})$ \\
\hline FRANCE & $\begin{array}{c}0.97 \\
(0.93,1.01) \\
\end{array}$ & $\begin{array}{l}8.5090 \\
(28.63) \\
\end{array}$ & $\begin{array}{c}-0.1423 \\
(-1.00) \\
\end{array}$ & $\begin{array}{c}-0.0167 \\
(-0.22) \\
\end{array}$ & $\begin{array}{c}-0.0106 \\
(-0.21) \\
\end{array}$ \\
\hline GERMANY & $\begin{array}{c}1.00 \\
(0.97,1.04)\end{array}$ & $\begin{array}{l}9.2435 \\
(31.81) \\
\end{array}$ & $\begin{array}{l}-0.2226 \\
(-1.26)\end{array}$ & $\begin{array}{c}-0.0400 \\
(-0.45) \\
\end{array}$ & $\begin{array}{c}-0.0182 \\
(-0.31)\end{array}$ \\
\hline ITALY & $\begin{array}{c}0.95^{*} \\
(0.92,0.98)\end{array}$ & $\begin{array}{l}10.0112 \\
(38.01)\end{array}$ & $\begin{array}{c}-0.0703 \\
(-0.44)\end{array}$ & $\begin{array}{c}-0.0122 \\
(-0.14)\end{array}$ & $\begin{array}{l}0.0110 \\
(0.19)\end{array}$ \\
\hline SPAIN & $\begin{array}{c}1.00 \\
(0.96,1.04)\end{array}$ & $\begin{array}{l}9.2859 \\
(28.63) \\
\end{array}$ & $\begin{array}{c}-0.0458 \\
(-0.23) \\
\end{array}$ & $\begin{array}{c}-0.0304 \\
(-0.30) \\
\end{array}$ & $\begin{array}{c}0.0148 \\
(0.22) \\
\end{array}$ \\
\hline U.K. & $\begin{array}{c}0.97 \\
(0.93,1.01)\end{array}$ & $\begin{array}{l}8.8027 \\
(49.08) \\
\end{array}$ & $\begin{array}{c}-0.0793 \\
(-0.73)\end{array}$ & $\begin{array}{c}-0.0064 \\
(-0.11) \\
\end{array}$ & $\begin{array}{c}-0.0287 \\
(-0.76) \\
\end{array}$ \\
\hline
\end{tabular}


Table 5: Estimated coefficients in a nonlinear $\mathrm{I}(\mathrm{d})$ model for the return series

\begin{tabular}{|c|c|c|c|c|c|}
\hline \multicolumn{6}{|c|}{ i) Monthly data } \\
\hline Series & $\mathrm{d}$ & $\theta_{0}$ & $\theta_{1}$ & $\theta_{2}(\mathrm{NL})$ & $\theta_{3}(\mathrm{NL})$ \\
\hline FRANCE & $\begin{array}{c}-0.12 \\
(-0.25,0.06)\end{array}$ & $\begin{array}{l}0.0040 \\
(1.66)\end{array}$ & $\begin{array}{c}0.0019 \\
(0.68)\end{array}$ & $\begin{array}{c}-0.0011 \\
(-0.39)\end{array}$ & $\begin{array}{c}0.0032 \\
(1.04)\end{array}$ \\
\hline GERMANY & $\begin{array}{c}-0.15 \\
(-0.29,0.05)\end{array}$ & $\begin{array}{c}\mathbf{0 . 0 0 7 8} \\
(3.30) \\
\end{array}$ & $\begin{array}{l}0.0053 \\
(1.90) \\
\end{array}$ & $\begin{array}{c}-0.0012 \\
(-0.41) \\
\end{array}$ & $\begin{array}{c}0.0036 \\
(1.14)\end{array}$ \\
\hline ITALY & $\begin{array}{c}-0.09 \\
(-0.20,0.07)\end{array}$ & $\begin{array}{c}0.0005 \\
(0.14)\end{array}$ & $\begin{array}{l}0.0007 \\
(0.03)\end{array}$ & $\begin{array}{c}-0.0017 \\
(-0.40)\end{array}$ & $\begin{array}{c}0.0033 \\
(0.72)\end{array}$ \\
\hline SPAIN & $\begin{array}{c}-0.06 \\
(-0.18,0.09)\end{array}$ & $\begin{array}{c}0.0003 \\
(0.08)\end{array}$ & $\begin{array}{l}0.0019 \\
(0.46)\end{array}$ & $\begin{array}{c}-0.0011 \\
(-0.27)\end{array}$ & $\begin{array}{l}0.0039 \\
(0.89)\end{array}$ \\
\hline U.K. & $\begin{array}{c}-0.21^{*} \\
(-0.33,-0.06) \\
\end{array}$ & $\begin{array}{l}0.0044 \\
(3.47) \\
\end{array}$ & $\begin{array}{c}0.0036 \\
(2.25) \\
\end{array}$ & $\begin{array}{c}0.0016 \\
(0.93)\end{array}$ & $\begin{array}{l}0.0022 \\
(1.17) \\
\end{array}$ \\
\hline \multicolumn{6}{|c|}{ i) Weekly data } \\
\hline Series & $\mathrm{d}$ & $\theta_{0}$ & $\theta_{1}$ & $\theta_{2}(\mathrm{NL})$ & $\theta_{3}(\mathrm{NL})$ \\
\hline FRANCE & $\begin{array}{c}-0.09^{*} \\
(-0.14,-0.02) \\
\end{array}$ & $\begin{array}{c}0.0009 \\
(1.30) \\
\end{array}$ & $\begin{array}{c}0.0004 \\
(0.51) \\
\end{array}$ & $\begin{array}{c}-0.0002 \\
(-0.36) \\
\end{array}$ & $\begin{array}{c}0.0007 \\
(0.88)\end{array}$ \\
\hline GERMANY & $\begin{array}{c}-0.06 \\
(-0.12,0.02)\end{array}$ & $\begin{array}{l}\mathbf{0 . 0 0 1 7} \\
(2.09)\end{array}$ & $\begin{array}{c}0.0012 \\
(1.32)\end{array}$ & $\begin{array}{c}-0.0003 \\
(-0.35)\end{array}$ & $\begin{array}{c}0.0008 \\
(0.88\end{array}$ \\
\hline ITALY & $\begin{array}{c}-0.02 \\
(-0.08,0.05)\end{array}$ & $\begin{array}{l}0.0005 \\
(0.04)\end{array}$ & $\begin{array}{l}-0.0003 \\
(-0.02)\end{array}$ & $\begin{array}{c}-0.0004 \\
(-0.36)\end{array}$ & $\begin{array}{l}0.0007 \\
(0.52)\end{array}$ \\
\hline SPAIN & $\begin{array}{c}-0.07^{*} \\
(-0.12,-0.01)\end{array}$ & $\begin{array}{c}0.0004 \\
(0.04) \\
\end{array}$ & $\begin{array}{c}0.0004 \\
(0.40)\end{array}$ & $\begin{array}{c}-0.0002 \\
(-0.20) \\
\end{array}$ & $\begin{array}{c}0.0009 \\
(0.86) \\
\end{array}$ \\
\hline U.K. & $\begin{array}{c}-0.10^{*} \\
(-0.16,-0.01) \\
\end{array}$ & $\begin{array}{c}\mathbf{0 . 0 0 1 0} \\
(\mathbf{1 . 9 5})\end{array}$ & $\begin{array}{c}0.0008 \\
(1.48) \\
\end{array}$ & $\begin{array}{c}0.0003 \\
(0.62) \\
\end{array}$ & $\begin{array}{c}0.0005 \\
(0.83) \\
\end{array}$ \\
\hline \multicolumn{6}{|c|}{ iii) Daily data } \\
\hline Series & $\mathrm{d}$ & $\theta_{0}$ & $\theta_{1}$ & $\theta_{2}(\mathrm{NL})$ & $\theta_{3}(\mathrm{NL})$ \\
\hline FRANCE & $\begin{array}{c}-0.03 \\
(-0.07,0.01)\end{array}$ & $\begin{array}{l}0.0001 \\
(0.47)\end{array}$ & $\begin{array}{c}-0.00005 \\
(-0.02)\end{array}$ & $\begin{array}{c}-0.0002 \\
(-1.04)\end{array}$ & $\begin{array}{c}-0.0001 \\
(-0.72)\end{array}$ \\
\hline GERMANY & $\begin{array}{c}-0.00 \\
(-0.03,0.04)\end{array}$ & $\begin{array}{l}0.0002 \\
(0.81)\end{array}$ & $\begin{array}{c}0.0001 \\
(0.44)\end{array}$ & $\begin{array}{c}-0.0002 \\
(-0.95)\end{array}$ & $\begin{array}{c}-0.0001 \\
(-0.38)\end{array}$ \\
\hline ITALY & $\begin{array}{c}-0.05^{*} \\
(-0.08,-0.02) \\
\end{array}$ & $\begin{array}{c}-0.00002 \\
(-0.09)\end{array}$ & $\begin{array}{c}-0.00006 \\
(-0.24)\end{array}$ & $\begin{array}{c}-0.0002 \\
(-1.06)\end{array}$ & $\begin{array}{c}-0.0003 \\
(-1.18)\end{array}$ \\
\hline SPAIN & $\begin{array}{c}-0.01 \\
(-0.04,0.03)\end{array}$ & $\begin{array}{c}-0.00005 \\
(-0.19)\end{array}$ & $\begin{array}{c}0.00001 \\
(0.03)\end{array}$ & $\begin{array}{c}-0.00002 \\
(-0.87)\end{array}$ & $\begin{array}{c}-0.0002 \\
(-0.97)\end{array}$ \\
\hline U.K. & $\begin{array}{c}-0.03 \\
(-0.06,0.01)\end{array}$ & $\begin{array}{c}0.00009 \\
(0.60)\end{array}$ & $\begin{array}{c}0.00005 \\
(0.31)\end{array}$ & $\begin{array}{c}-0.00004 \\
(0.23)\end{array}$ & $\begin{array}{c}0.00001 \\
(0.07)\end{array}$ \\
\hline
\end{tabular}


Table 6: Number of breaks in each series using Gil-Alana (2008)

\begin{tabular}{|c|c|c|}
\hline \multicolumn{3}{|r|}{ i) Monthly data } \\
\hline Series & N. breaks & Break dates \\
\hline FRANCE & 2 & September 2013 and March 2017 \\
\hline GERMANY & (4) 2 & (July 2010), (March 2012), September 2013 and December 2016 \\
\hline ITALY & 2 & August 2011 and January 2014 \\
\hline SPAIN & (3) 2 & August 2011, (September 2013) and December 2015 \\
\hline U.K. & (3) 2 & (July 2010), January 2013 and December 2016 \\
\hline \multicolumn{3}{|r|}{ ii) Weekly data } \\
\hline Series & N. breaks & Break dates \\
\hline FRANCE & (4) 2 & (August 2011), April 2013, (March 2015) and March 2017 \\
\hline GERMANY & (4) 2 & (July 2010), July 2013, (January 2015) and December 2016 \\
\hline ITALY & 4 & August 2011, October 2013, Novemebr 2015 and May 2017 \\
\hline SPAIN & 4 & August 2011, September 2013, December 2015 and June 2017 \\
\hline U.K. & (4) 2 & (July 2010), January 2013, (June 2015) and December 2016 \\
\hline \multicolumn{3}{|r|}{ iii) Daily data } \\
\hline Series & N. breaks & Break dates \\
\hline FRANCE & 4 & June 2012, September 2013, January 2015, March 2017 \\
\hline GERMANY & 4 & August 2012, November 2013, February 2015, December 2016 \\
\hline ITALY & 4 & March 2012, October 2013, January 2016 nd March 2017 \\
\hline SPAIN & 4 & March 2012, September 2013, December 2016 and February 2017 \\
\hline U.K. & 4 & February 2013, May 2014, August 2015 nd December 2016 \\
\hline
\end{tabular}


Table 7: Estimates of $d$ for each country and each subsample with MONTHLY data

\begin{tabular}{|c|c|c|c|c|}
\hline Country & Subsamples & No terms & An intercept & A linear trend \\
\hline \multirow{3}{*}{ FRANCE } & 1st subsample & $0.93(0.77,1.17)$ & $0.93(0.73,1.23)$ & $0.94(0.76,1.22)$ \\
\hline & 2nd subsmple & $0.92(0.72,1.21)$ & $0.67(0.42,1.03)$ & $0.71(0.49,1.04)$ \\
\hline & 3rd subsample & $0.82(0.48,1.26)$ & $0.73(0.43,1.10)$ & $0.72(0.45,1.11)$ \\
\hline \multirow{3}{*}{ GERMANY } & 1st subsample & $0.93(0.77,1.16)$ & $0.83(0.61,1.19)$ & $0.85(0.67,1.18)$ \\
\hline & 2nd subsmple & $0.91(0.70,1.21)$ & $0.75(0.44,1.25)$ & $0.80(0.52,1.24)$ \\
\hline & 3rd subsample & $0.84(0.55,1.24)$ & $0.95(0.72,1.31)$ & $0.94(0.70,1.31)$ \\
\hline \multirow{3}{*}{ ITALY } & 1st subsample & $0.86(0.62,1.20)$ & $0.76(0.50,1.31)$ & $0.76(0.49,1.32)$ \\
\hline & 2nd subsmple & $0.86(0.60,1.23)$ & $0.63(0.41,0.96)$ & $0.57^{*}(0.31,0.96)$ \\
\hline & 3rd subsample & $0.95(0.79,1.18)$ & $0.93(0.77,1.14)$ & $0.93(0.77,1.14)$ \\
\hline \multirow{3}{*}{ SPAIN } & 1st subsample & $0.86(0.62,1.20)$ & $0.90(0.64,1.35)$ & $0.90(0.66,1.35)$ \\
\hline & 2nd subsmple & $0.93(0.75,1.18)$ & $0.90(0.76,1.12)$ & $0.89(0.73,1.12)$ \\
\hline & 3rd subsample & $0.89(0.67,1.20)$ & $0.83(0.67,1.07)$ & $0.84(0.68,1.07)$ \\
\hline \multirow{3}{*}{ UK } & 1st subsample & $0.92(0.74,1.18)$ & $0.86(0.64,1.18)$ & $0.87(0.71,1.16)$ \\
\hline & 2nd subsmple & $0.89(0.66,1.22)$ & $0.50^{*}(0.24,0.73)$ & $0.50(0.33,0.73)$ \\
\hline & 3rd subsample & $0.90(0.68,1.21)$ & $0.89(0.73,1.12)$ & $0.89(0.73,1.12)$ \\
\hline
\end{tabular}


Table 8: Estimates of $d$ for each country and each subsample with WEEKLY data

\begin{tabular}{|c|c|c|c|c|}
\hline Country & Subsamples & No terms & An intercept & A linear trend \\
\hline \multirow{3}{*}{ FRANCE } & 1st subsample & $0.98(0.90,1.09)$ & $0.92(0.83,1.03)$ & $0.92(0.84,1.03)$ \\
\hline & 2nd subsmple & $0.98(0.90,1.10)$ & $0.90(0.80,1.04)$ & $0.91(0.81,1.04)$ \\
\hline & 3rd subsample & $0.96(0.84,1.14)$ & $0.88(0.76,1.06)$ & $0.88(0.75,1.06)$ \\
\hline Country & Subsamples & No terms & An intercept & A linear trend \\
\hline \multirow{3}{*}{ GERMANY } & 1st subsample & $0.98(0.90,1.08)$ & $0.97(0.88,1.08)$ & $0.97(0.88,1.08)$ \\
\hline & 2nd subsmple & $0.98(0.89,1.11)$ & $0.92(0.81,1.06)$ & $0.92(0.82,1.06)$ \\
\hline & 3rd subsample & $0.97(0.85,1.14)$ & $0.91(0.81,1.05)$ & $0.91(0.81,1.05)$ \\
\hline Country & Subsamples & No terms & An intercept & A linear trend \\
\hline \multirow{5}{*}{ ITALY } & 1st subsample & $0.96(0.86,1.10)$ & $0.98(0.85,1.14)$ & $0.98(0.85,1.14)$ \\
\hline & 2nd subsmple & $0.96(0.85,1.12)$ & $0.87(0.74,1.04)$ & $0.87(0.73,1.04)$ \\
\hline & 3rd subsample & $0.97(0.85,1.15)$ & $0.89(0.76,1.08)$ & $0.89(0.76,1.08)$ \\
\hline & 4th subsample & $0.95(0.80,1.16)$ & $1.07(0.90,1.33)$ & $1.07(0.90,1.33)$ \\
\hline & 5th subsample & $0.97(0.84,1.13)$ & $0.96(0.84,1.15)$ & $0.96(0.84,1.15)$ \\
\hline Country & Subsamples & No terms & An intercept & A linear trend \\
\hline \multirow{5}{*}{ SPAIN } & 1st subsample & $0.97(0.86,1.11)$ & $0.92(0.82,1.06)$ & $0.92(0.82,1.06)$ \\
\hline & 2nd subsmple & $0.97(0.85,1.14)$ & $0.88(0.77,1.03)$ & $0.88(0.77,1.03)$ \\
\hline & 3rd subsample & $0.97(0.86,1.15)$ & $0.81(0.68,0.99)$ & $0.82(0.69,0.99)$ \\
\hline & 4th subsample & $0.95(0.82,1.15)$ & $0.95(0.81,1.20)$ & $0.95(0.78,1.21)$ \\
\hline & 5th subsample & $0.96(0.82,1.14)$ & $0.70(0.60,0.90)$ & $0.65(0.49,0.89)$ \\
\hline Country & Subsamples & No terms & An intercept & A linear trend \\
\hline \multirow{3}{*}{ UK } & 1st subsample & $0.98(0.90,1.09)$ & $0.91(0.82,1.03)$ & $0.92(0.83,1.03)$ \\
\hline & 2nd subsmple & $0.98(0.89,1.09)$ & $0.85(0.75,0.99)$ & $0.85(0.75,0.99)$ \\
\hline & 3rd subsample & $0.97(0.85,1.13)$ & $0.97(0.84,1.16)$ & $0.97(0.84,1.16)$ \\
\hline
\end{tabular}


Table 9: Estimates of $d$ for each country and each subsample with DAILY data

\begin{tabular}{|c|c|c|c|c|}
\hline Country & Subsamples & No terms & An intercept & A linear trend \\
\hline \multirow{5}{*}{ FRANCE } & 1st subsample & $0.99(0.92,1.07)$ & $0.98(0.91,1.08)$ & $0.98(0.91,1.08)$ \\
\hline & 2nd subsmple & $0.99(0.92,1.08)$ & $0.87(0.78,0.97)$ & $0.88^{*}(0.79,0.98)$ \\
\hline & 3rd subsample & $0.99(0.92,1.07)$ & $0.92(0.85,1.01)$ & $0.92(0.85,1.01)$ \\
\hline & 4th subsample & $0.99(0.94,1.06)$ & $0.96(0.90,1.04)$ & $0.96(0.90,1.04)$ \\
\hline & 5th subsample & $0.99(0.93,1.06)$ & $1.00(0.94,1.07)$ & $1.00(0.94,1.07)$ \\
\hline Country & Subsamples & No terms & An intercept & A linear trend \\
\hline \multirow{5}{*}{ GERMANY } & 1st subsample & $0.99(0.93,1.07)$ & $1.05(0.98,1.15)$ & $1.05(0.98,1.15)$ \\
\hline & 2nd subsmple & $0.99(0.92,1.09)$ & $0.91(0.83,1.02)$ & $0.92(0.84,1.02)$ \\
\hline & 3rd subsample & $0.99(0.92,1.08)$ & $0.96(0.88,1.05)$ & $0.96(0.89,1.05)$ \\
\hline & 4th subsample & $0.99(0.94,1.06)$ & $0.99(0.93,1.07)$ & $0.99(0.93,1.07)$ \\
\hline & 5th subsample & $0.99(0.94,1.06)$ & $0.97(0.92,1.03)$ & $0.97(0.92,1.03)$ \\
\hline Country & Subsamples & No terms & An intercept & A linear trend \\
\hline \multirow{5}{*}{ ITALY } & 1st subsample & $0.99(0.92,1.08)$ & $0.99(0.91,1.09)$ & $0.99(0.91,1.09)$ \\
\hline & 2nd subsmple & $0.99(0.93,1.07)$ & $0.96(0.88,1.03)$ & $0.96(0.88,1.03)$ \\
\hline & 3rd subsample & $0.99(0.94,1.06)$ & $0.90^{*}(0.85,0.96)$ & $0.90(0.85,0.96)$ \\
\hline & 4th subsample & $0.97(0.91,1.07)$ & $0.91(0.84,1.00)$ & $0.91(0.83,1.00)$ \\
\hline & 5th subsample & $0.99(0.93,1.06)$ & $0.95(0.90,1.02)$ & $0.95(0.90,1.02)$ \\
\hline Country & Subsamples & No terms & An intercept & A linear trend \\
\hline \multirow{5}{*}{ SPAIN } & 1st subsample & $0.99(0.92,1.07)$ & $1.02(0.92,1.15)$ & $1.02(0.92,1.15)$ \\
\hline & 2nd subsmple & $0.99(0.93,1.07)$ & $1.01(0.94,1.09)$ & $1.01(0.94,1.09)$ \\
\hline & 3rd subsample & $1.00(0.95,1.05)$ & $0.97(0.92,1.04)$ & $0.97(0.92,1.04)$ \\
\hline & 4th subsample & $0.94(0.77,1.17)$ & $0.49(0.31,0.92)$ & $0.63^{*}(0.39,0.94)$ \\
\hline & 5th subsample & $0.99(0.94,1.06)$ & $0.98(0.92,1.05)$ & $0.98(0.92,1.05)$ \\
\hline Country & Subsamples & No terms & An intercept & A linear trend \\
\hline \multirow{5}{*}{ UK } & 1st subsample & $0.99(0.94,1.06)$ & $0.97(0.90,1.06)$ & $0.97(0.90,1.06)$ \\
\hline & 2nd subsmple & $0.99(0.92,1.07)$ & $0.98(0.90,1.07)$ & $0.98(0.90,1.07)$ \\
\hline & 3rd subsample & $0.99(0.92,1.07)$ & $1.01(0.92,1.12)$ & $1.01(0.92,1.12)$ \\
\hline & 4th subsample & $0.99(0.92,1.07)$ & $0.94(0.86,1.04)$ & $0.94(0.86,1.04)$ \\
\hline & 5th subsample & $0.99(0.94,1.06)$ & $0.97(0.92,1.03)$ & $0.97(0.92,1.03)$ \\
\hline
\end{tabular}




\section{Appendices}

\section{Appendix 1. Monthly stock indices}

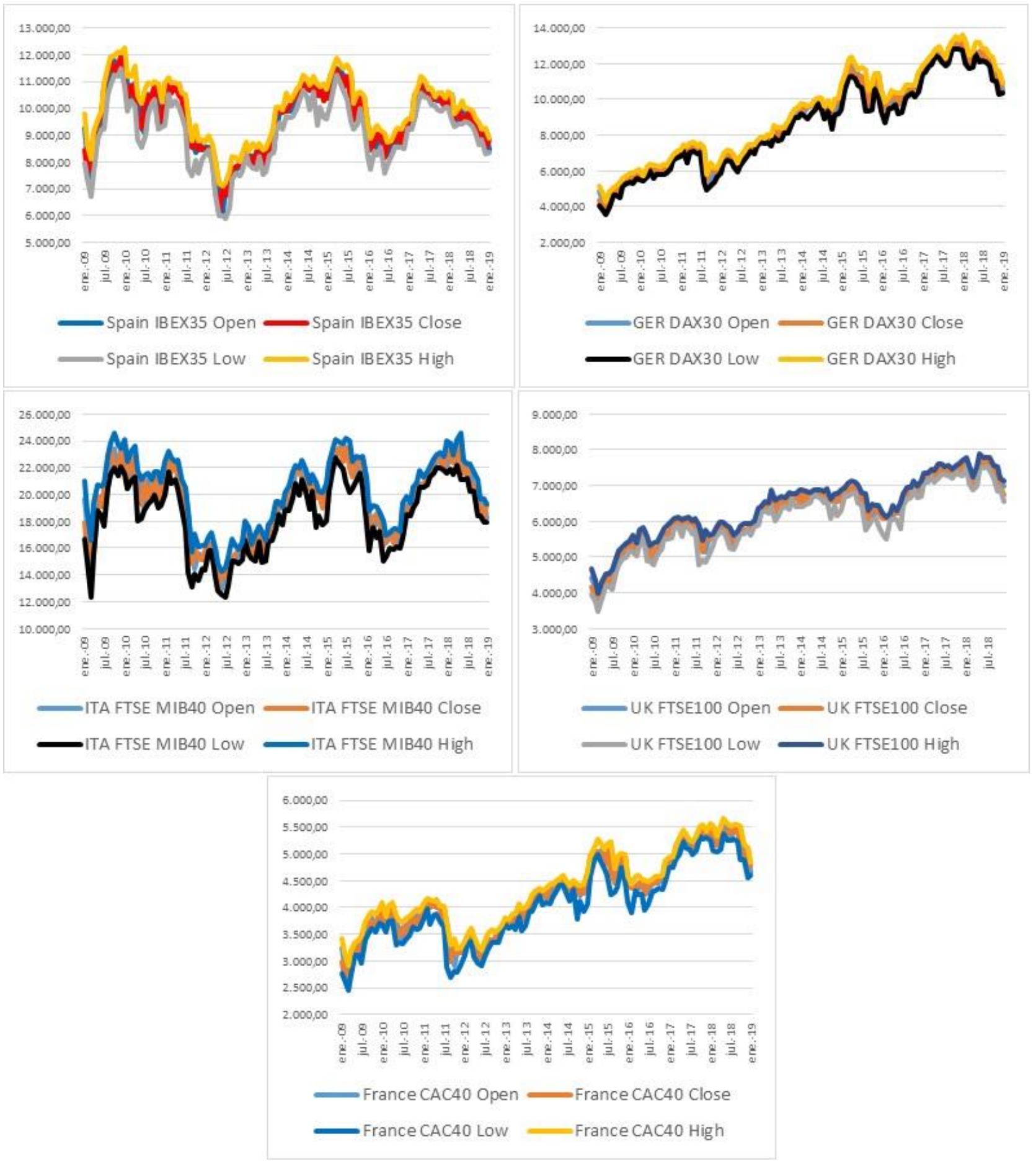




\section{Appendix 2. Weekly stock indices}

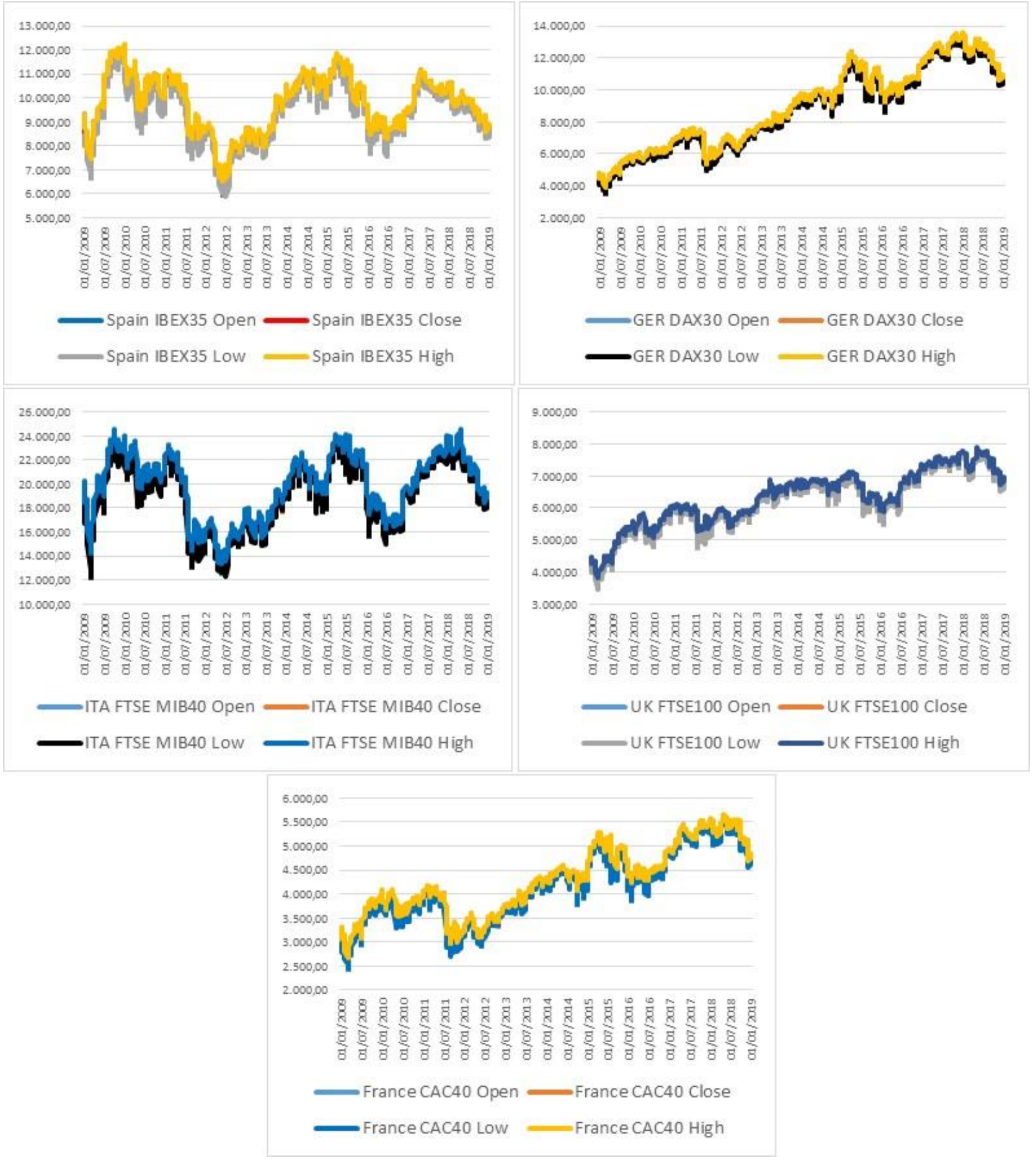




\section{Appendix 3. Daily stock indices}

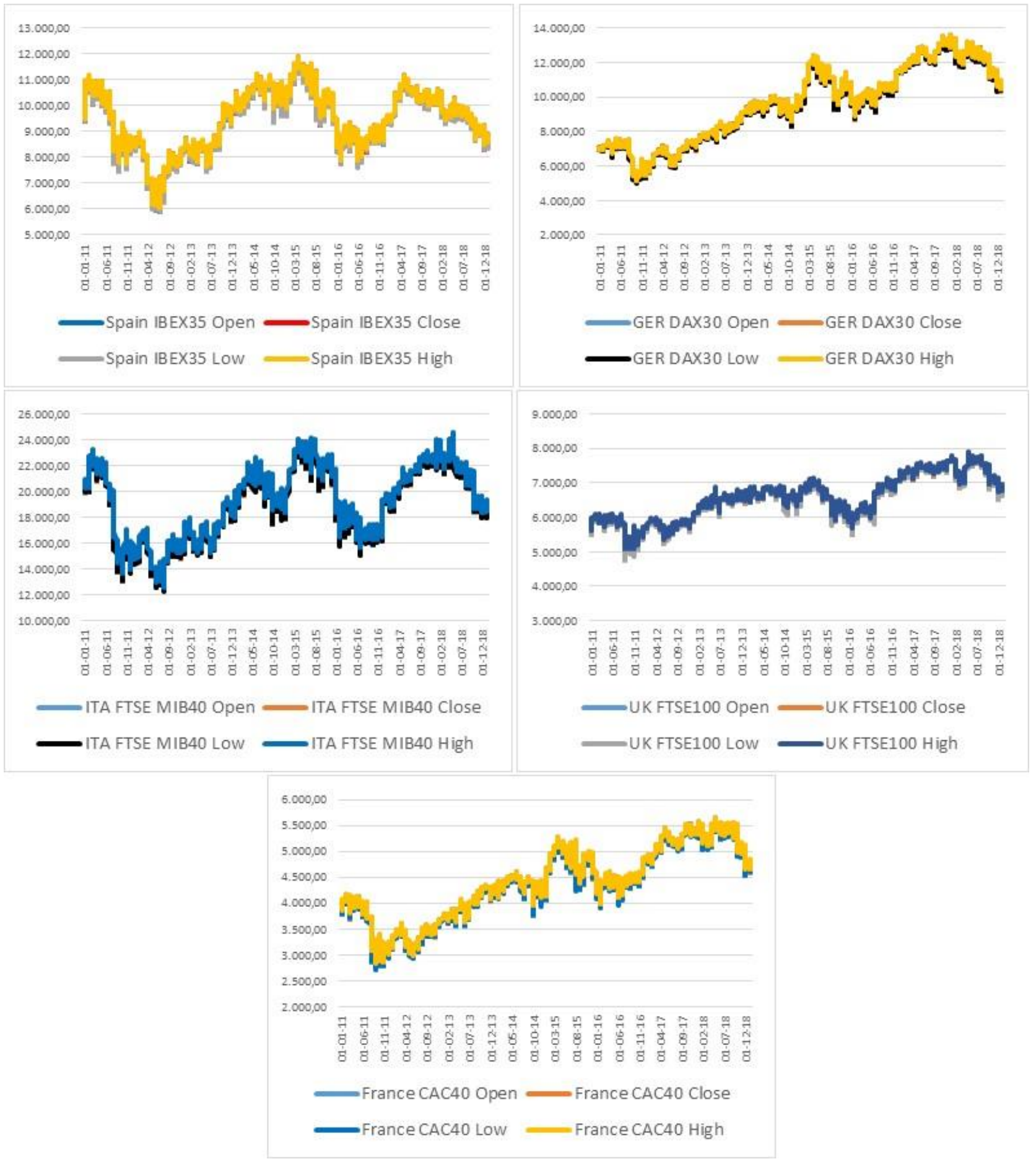

